\title{
ANALISIS KEMAMPUAN TIGA LEVEL REPRESENTASI SISWA PADA KONSEP ASAM-BASA MENGGUNAKAN KERANGKA DAC (DEFINITION, ALGORITHMIC, CONCEPTUAL)
}

\author{
Citra Wulan Sari ${ }^{1}$ dan Imelda Helsy ${ }^{2}$ \\ ${ }^{1}$ SMA Taman Siswa, Jl. Rancanilem Rancaekek, Bandung, 40394, Indonesia \\ ${ }^{2}$ Prodi pendidikan Kimia UIN Bandung, Jl A. H Nasution No 105, Bandung, 40614, Indonesia \\ ${ }^{1}$ E-mail: citrawulansari19@gmail.com
}

\begin{abstract}
ABSTRAK
Telah dilakukan penelitian yang ditujukan untuk menganalisis kemampuan tiga level representasi kimia pada konsep asam basa dengan menggunakan tes essay yang mengacu kepada kerangka DAC (Definition, Algorithmic Conceptual). Penelitian dilakukan terhadap 48 orang siswa sekolah menengah atas di wilayah Bandung. Indikator kemampuan representasi yang dianalisis mencakup kemampuan siswa dalam menghubungkan representasi simbolik ke submikroskopik, makroskopik ke simbolik, makroskopik ke submikroskopik dan simbolik serta makroskopik ke submikroskopik. Hasil penelitian menunjukkan secara keseluruhan siswa lebih berhasil merepresentasikan makroskopik ke submikroskopik dibandingkan dengan kemampuan representasi lainnya. Namun teridentifikasi potensi miskonsepsi pada sebagian besar siswa adalah mengenai konsep kekuatan asam-basa dan $\mathrm{pH}$. Pencapaian terendah pada kemampuan representasi makroskopik ke simbolik yaitu pada penyelesaian soal yang membutuhkan langkah-langkah pengerjaan secara matematis dan melibatkan rumus atau perhitungan yang beragam (type A-Mu: Alghoritmic Multistep).
\end{abstract}

Kata kunci: kemampuan representasi kimia, kerangka $D A C$, konsep asam-basa.

\section{ABSTRACT}

Research has been conducted to analyze the ability of three levels of chemical representation on the concept of acid base by using essay test which refers to the DAC (Definition, Algorithmic, and Conceptual) framework. The study was conducted on 48 high school students in Bandung. Indicators of representational ability analyzed include students' ability in connecting symbolic representations to submicroscopic, macroscopic to symbolic, macroscopic to submicroscopic and symbolic and macroscopic to submicroscopic. The results showed overall the students were more successful representing the macroscopic to submicroscopic than other representational capabilities. The best achievement of representational ability is to interpret data that connects macroscopic representation to submicroscopic. However, potential misconceptions are identified in most students regarding the concept of acid-base strength and $\mathrm{pH}$. The lowest achivement is on macroscopic representation to symbolic; on solving problems that require mathematical processing steps and involve diverse formulas or calculations.

Keywords: chemical representation ability, DAC framework, acid-base concept.

DOI: https://doi.org/10.15575/jtk.v3i2.3660 


\section{PENDAHULUAN}

Keberhasilan siswa dalam belajar kimia ditunjukkan oleh kemampuannya untuk memecahkan masalah menggunakan tiga level representasi kimia, yaitu level representasi makroskopik, submikroskopik dan simbolik (Farida et al., 2017). Karena itu, kemampuan representasi sangat penting dikembangkan dalam pembelajaran kimia.

Kinerja kompetensi representasi mencakup: kemampuan menggunakan representasi untuk mendeskripsikan dan menjelaskan fenomena kimia dalam term yang dilandasi entitas dan proses molekuler (level submikroskopik); memilih, menganalisis dan membuat hubungan pola-pola fitur-fitur representasi tertentu; dan menggunakan representasi dan fitur-fiturnya dalam situasi sosial untuk membuat inferensi dan prediksi tentang fenomena kimia yang diobservasi (Michalchik et al., 2008).

Salah satu konsep kimia yang memiliki karakteristik ketiga level representasi adalah konsep asam basa. Kajian terhadap konsep ini, menunjukkan fenomena kontekstual secara makroskopik dapat dipelajari antara lain dari fenomena hujan asam dan kesetimbangan asam-basa dalam sistem tubuh. Secara konseptual, fenomena makroskopik dipelajari di laboratorium melalui praktikum penentuan $\mathrm{pH}$ menggunakan berbagai indikator, kekuatan asam-basa dan titrasi asam-basa. Level representasi submikroskopik dapat ditunjukkan dengan memvisualisasikan terjadinya transfer proton saat suatu asam atau basa terlarut dalam air, keadaan kesetimbangan ion-ion dan molekul-molekul dalam larutan asam dan basa untuk memvisualisasikan perbedaan $\mathrm{pH}$ dan kekuatan asam dan basa. Secara simbolik berkaitan dengan persamaan reaksi transfer proton dalam larutan asam atau larutan basa dan penentuan $\mathrm{pH}$ larutan (Gilbert et al., 2018). Konsep asam-basa memiliki tingkat kesulitan secara konseptual yang tinggi, meskipun fenomenanya mudah ditemukan dalam kehidupan sehari-hari. Hal itu, karena pemahaman terhadap konsep asam basa memerlukan integrasi dengan konsep lain seperti sifat partikel materi, sifat dan komposisi larutan, struktur atom, ikatan ionik dan kovalen, simbol, persamaan reaksi, ionisasi dan kesetimbangan kimia dalam fasa larutan (Sheppard, 2006).

Selain itu, konsep asam-basa menekankan pada dua komponen yaitu algoritmik dan konseptual (Drechsler \& Schmidt, 2005). Algoritmik terdapat pada penentuan konsentrasi larutan asam basa, $\mathrm{pH}$ atau $\mathrm{pOH}$, mencari $K_{a}$ dan $K_{b}$, serta persen ionisasi sedangkan konseptual meliputi penjelasan mengenai berbagai fenomena asam dan basa dalam kehidupan. Kedua komponen tersebut perlu dipahami dengan baik oleh siswa karena melalui konsep ini siswa akan terbantu dalam memahami konsep selanjutnya seperti larutan penyangga dan hidrolisis garam.

Tingkat kesulitan yang tinggi tersebut menjadi dasar pentingnya menganalisis lebih mendalam perolehan konsepsi yang dimiliki siswa dengan mengkaitkannya dengan ketiga level representasi. Hal itu ditujukan agar potensi kesalahan konsep yang terjadi pada siswa bisa dicarikan alternatif solusinya dengan memperbaiki strategi pembelajaran, sehingga tidak menimbulkan miskonsepsi yang akan terbawa pada pendidikan di tingkat lebih atas (Stoyanovich et al., 2015).

Kemampuan representasi kimia tersebut dapat diukur menggunakan berbagai metode dan instrumen pengukuran. Identifikasi Jurnal Tadris Kimiya 3, 2 (Desember 2018): 158-170

This is an open access article under CC-BY-SA license (https://creativecommons.org/licenses/by-sa/4.0/) 
kemampuan representasi siswa penting untuk mengetahui keberhasilan pembelajaran yang telah dilaksanakan guru (Bayrak, 2013). Di sekolah, kemampuan representasi belum biasa diukur dengan menggunakan instrumen yang dikhususkan untuk keperluan tersebut. Umumnya guru mengukur ketiga level representasi tersebut secara terpisah dengan kecenderungan lebih memfokuskan pada pengukuran level representasi simbolik.

Berbagai penelitian telah dikembangkan untuk menganalisis kemampuan representasi siswa pada konsep asam-basa. Sopandi dan Murniati (2007) meneliti menggunakan tes tertulis pilihan berganda, temuan penelitian menyatakan siswa lebih banyak mengalami miskonsepsi pada level submikroskopik dan simbolik dibandingkan dengan level makroskopik. Indriyani (2013) mengukur kemampuan representasi makroskopik, simbolik dan submikroskopik pada konsep tirasi asam basa dengan menggunakan tes uraian. Hasil penelitian menunjukkan siswa memiliki kemampuan representasi makroskopik yang tinggi, namun terdapat miskonsepsi mengenai penggunaan indikator. Kemampuan siswa memahami level simbolik dan submikroskopik sangat rendah. Pengukuran kemampuan siswa memahami konsep asam basa dilaporkan dari berbagai penelitian melalui tes diagnostik berbentuk pilihan berganda dengan alasan pemilihan jawaban dalam bentuk pilihan berganda (twotier multiple choice), (Chandrasegaran et al., 2007) three-tier multiple choice (Cetin-dindar \& Geban, 2011), tes diagnostic asam basa berbentuk survey (Stoyanovich et al., 2015), penggabungan wawancara dengan tugas berbasis komputer (Sheppard, 2006), dan penugasan dengan menggunakan evidence centered design (ECD) framework (Cooper et al., 2016). Umumnya temuan dari penelitian tersebut menyatakan lemahnya kemampuan siswa dalam menghubungkan fenomena yang diamati dengan kerangka konseptual yang harus dikuasainya untuk digunakan dalam pemecahan masalah, baik yang bersifat kontekstual maupun algoritmik. Terjadi kecenderungan siswa yang sukses menyelesaikan soal perhitungan (algoritmik) belum tentu mampu menyelesaikan soal-soal yang berkaitan dengan konseptual. Ini menunjukkan kemampuan representasi simbolik yang dikuasai siswa, tidak terhubung dengan kemampuan representasi makroskopik dan simbolik. Mereka tidak mampu menyelesaikan perhitungan algoritmik karena tidak memahami konsep kimia yang mendasarinya.

Smith et al. (2010) menyarankan perluasan kerangka kerja untuk pengukuran kemampuan siswa menyelesaikan permasalahan kimia yaitu mengkategorikan pertanyaan yang menyeimbangkan komponen algoritmik dan konseptual dalam bentuk kerangka DAC (definition, algorithmic, Conceptual) dengan mengacu pada tiga level representasi kimia, yaitu makroskopik, submikroskopik dan simbolik dan level kognitif serta Taksonomi Bloom Revisi. Bagan kerangka $D A C$ dapat dilihat pada Gambar 1. Berikut ini penjelasan kerangka DAC disarikan dari Smith et al. (2010):

Definition (D): jika pertanyaan definisi diberikan sebagai pertanyaan uraian, maka untuk menjawab pertanyaan definisi siswa harus mengingat-ingat kembali informasi terkait, dan/atau memahami dan/atau menerapkan definisi. Jika pertanyaan definisi diberikan dalam format pilihan ganda, maka siswa harus mengenali definisi berdasarkan option jawaban. Ada dua kategori definisi yaitu: a) Recall, Understand, or Apply a definition (D-RUA): pertanyaan dengan kategori mengingat, memahami, dan/atau Jurnal Tadris Kimiya 3, 2 (Desember 2018): 158-170 

Siswa pada Konsep Asam-Basa menggunakan Kerangka DAC (Definition, Algorithmic, Conceptual)

menerapkan definisi; b) Recognize a Definition $(D-R)$ : pertanyaan pilihan ganda untuk mengingat kembali suatu definisi berdasarkan clue yang diberikan.

Alghorithmic $(A)$ : pertanyaan berupa representasi kimia yang ditampilkan dalam perhitungan berkaitan dengan jumlah yang melibatkan level makroskopik, jumlah atau massa partikel level submikroskopik dan simbol kimia. Representasi makroskopik merupakan data makro yang dapat terlihat secara kasat mata atau dapat dibaca dengan alat ukur, contoh: Massa, volume atau pH. Representasi submikroskopik berupa data mikro yang tidak terlihat dengan kasat mata seperti mol dan jumlah partikel, sedangkan representasi simbolik merupakan data persamaan reaksi. Ada empat kategori yaitu:

a) Macroscopic-Microscopic Conversions Question (A-MaMi): penyelesaian soal yang memerlukan konversi antara jumlah yang melibatkan makroskopik dengan jumlah yang melibatkan mikroskopik;

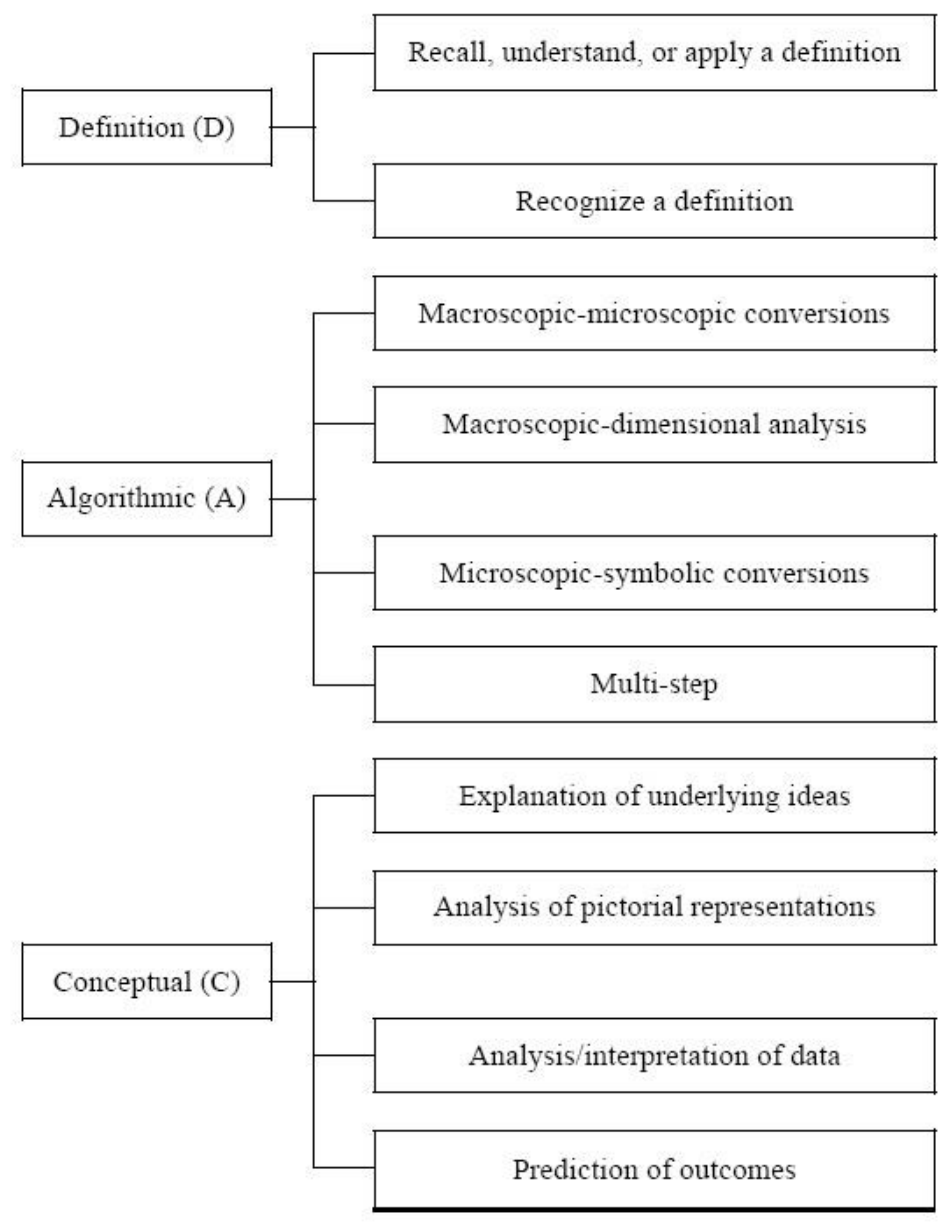

Gambar 1. Bagan Kerangka DAC (Smith et al., 2010) 
b) Macroscopic-Dimensional Analysis Question $(A-M a D)$ memerlukan konversi antara unit kuantitas makroskopik. Siswa dituntut untuk mengkonversi unit kuantitas makroskopik tersebut melalui proses analisis dimensi menggunakan faktor konversi sebelum mencari jawaban untuk memperoleh nilai yang dicari; c) Microscopic-Symbolic Conversion Question (A-MiS): membutuhkan konversi unit mikroskopik yang didasarkan pada rumus kimia atau persamaan; d) MultiStep Questions $(A-M u)$ penyelesaian soal yang membutuhkan langkah-langkah pengerjaan secara matematis dan melibatkan rumus atau perhitungan yang berbeda. Berdasarkan keempat kategori, kemampuan representasi yang terukur adalah konversi representasi makroskopik ke representasi simbolik karena permasalahan dalam soal perhitungan termasuk dalam level makroskopik dan penyelesaian permasalahan dengan perhitungan merupakan kemampuan dalam level simbolik.

Conceptual (C); Pada tingkat konseptual, ada empat jenis pengkodean pada kategori ini yaitu: a) Explanation of Underlying Ideas (C-E); Pertanyaan yang melibatkan pengamatan dari sebuah fenomena kimia dan memerlukan eksplanasi fenomena secara submikroskopik. b) Analysis of Pictorial Representations (C-P); Pertanyaan yang melibatkan analisis representasi bergambar secara submikroskopik atau berupa simbol kimia dan/atau persamaan. C) Analysis/Interpretation of Data (C-I); Pertanyaan yang melibatkan analisis atau interpretasi data serangkaian pola data dalam bentuk tabel, grafik atau deskripsi kualitatif. d) Prediction of Outcome (C-O); Pertanyaan yang melibatkan prediksi hasil (C-O). Pertanyaan-pertanyaan ini menghadirkan situasi kimia dan memerlukan prediksi hasil.
Penggunaan kerangka DAC dianggap paling relevan untuk mengukur kemampuan tiga level representasi, karena setiap kategori pada kerangka DAC memuat hubungan antar level representasi. Berdasarkan kerangka $D A C$, peneliti telah menyusun tes uraian untuk menganalisis kemampuan tiga level representasi pada konsep asam basa. Bentuk tes uraian dipilih agar dapat ditelusuri pola berpikir siswa berdasarkan jawaban yang diberikan dan meminimalisir resiko penebakan jawaban (Farida, 2017). Pada penelitian, masalah yang ingin dicari jawabannya adalah bagaimana kerangka $D A C$ diterapkan untuk menganalisis kemampuan tiga level representasi siswa pada konsep asam-basa dengan teknik pemberian tes yang berbeda.

\section{METODE PENELITIAN}

Metode penelitian yang digunakan pada penelitian ini adalah penelitian deskriptif, karena peneliti bermaksud mendeskripsikan kemampuan tiga level representasi siswa pada konsep asam-basa. Subyek penelitian melibatkan siswa kelas XI salah satu SMA di Kabupaten Bandung dengan sampel penelitian sebanyak 48 orang. Untuk keperluan analisis data, siswa dikategorikan ke dalam kelompok tinggi, sedang dan rendah. Dasar pengelompokkan tersebut diperoleh dari nilai rerata ulangan harian. Hasil pengelompokan siswa diperoleh data sebagai berikut: kelompok siswa prestasi tinggi 11 orang, prestasi sedang 29 orang dan prestasi rendah 8 orang.

Pada Tabel 1 disajikan hubungan indikator soal dengan kemampuan tiga level representasi berdasarkan kerangka DAC. Perangkat tes yang telah disusun sebelum digunakan diuji validitas kontennya oleh tiga validator ahli. Setelah itu, dilakukan uji coba Jurnal Tadris Kimiya 3, 2 (Desember 2018): 158-170 
terhadap 40 siswa kelas XI untuk mengetahui validitas, reliabilitas, tingkat kesukaran dan daya pembeda butir-butir tes

Tabel 1. Hubungan Indikator Soal dengan Kemampuan Tiga Level Representasi berdasarkan Kerangka DAC

\begin{tabular}{|c|c|c|c|}
\hline $\begin{array}{l}\text { No } \\
\text { Soal }\end{array}$ & $\begin{array}{l}\text { Kode Tipe } \\
\text { DAC }\end{array}$ & Level representasi & Indikator soal \\
\hline 1 & $D-R U A$ & $\begin{array}{l}\text { Simbolik- } \\
\text { Submikroskopik }\end{array}$ & $\begin{array}{l}\text { Diberikan representasi simbolik reaksi kimia, siswa dapat } \\
\text { mengenali reaksi tersebut untuk mendefinisikan asam basa } \\
\text { berdasarkan teori yang dikemukakan ahli. }\end{array}$ \\
\hline 2 & A-MaMi & $\begin{array}{l}\text { Makroskopik- } \\
\text { Simbolik }\end{array}$ & $\begin{array}{l}\text { Diberikan data pH suatu larutan, siswa dapat } \\
\text { mengkonversi unit makroskopik (nilai pH dan volume) ke } \\
\text { dalam unit submikroskopik (mol) dalam representasi } \\
\text { simbolik. }\end{array}$ \\
\hline 3 & $A-M a D$ & $\begin{array}{l}\text { Makroskopik- } \\
\text { Simbolik }\end{array}$ & $\begin{array}{l}\text { Diberikan data massa suatu zat dalam (satuan } \mathrm{mg} \text { ), siswa } \\
\text { dapat menentukan } \mathrm{pH} \text { dengan mengkonversi satuan unit } \\
\text { makroskopik menggunakan analisis multidimensional. }\end{array}$ \\
\hline 4 & $A-M u$ & $\begin{array}{l}\text { Makroskopik- } \\
\text { Simbolik }\end{array}$ & $\begin{array}{l}\text { Diberikan data konsentrasi suatu larutan, siswa dapat } \\
\text { menentukan pH larutan tersebut melalui beberapa langkah } \\
\text { penyelesaian perhitungan. }\end{array}$ \\
\hline 5 & $C-E$ & $\begin{array}{l}\text { Makroskopik- } \\
\text { Submikroskopik- } \\
\text { Simbolik }\end{array}$ & $\begin{array}{l}\text { Diberikan gambar mengenai fenomena konsep asam basa } \\
\text { dalam kehidupan, siswa dapat mengeksplanasi fenomena } \\
\text { tersebut berdasarkan representasi submikroskopik dan } \\
\text { simbolik. }\end{array}$ \\
\hline 6 & $C-P$ & $\begin{array}{l}\text { Simbolik- } \\
\text { Submikroskopik }\end{array}$ & $\begin{array}{l}\text { Berdasarkan diagram representasi submikroskopik larutan } \\
\text { yang berbeda kekuatan asam/basa, namun konsentrasi } \\
\text { sama, siswa dapat menganalisis asam yang terkuat beserta } \\
\text { penjelasan berdasarkan hasil ionisasi. }\end{array}$ \\
\hline 7 & $C-I$ & $\begin{array}{l}\text { Makroskopik- } \\
\text { Submikroskopik }\end{array}$ & $\begin{array}{l}\text { Diberikan representasi makroskopik data } K_{a} \text { dan } \mathrm{pH} \text { asam, } \\
\text { siswa dapat mengurutkan asam terlemah sampai terkuat } \\
\text { beserta penjelasan secara submikroskopik. }\end{array}$ \\
\hline 8 & $\mathrm{C}-\mathrm{O}$ & $\begin{array}{l}\text { Makroskopik- } \\
\text { Submikroskopik }\end{array}$ & $\begin{array}{l}\text { Diberikan dua keadaan yang berbeda mengenai suatu } \\
\text { fenomena, siswa dapat memprediksi efek yang terjadi } \\
\text { akibat kondisi yang berbeda disertai alasan secara } \\
\text { submikroskopik }\end{array}$ \\
\hline
\end{tabular}

Hasil uji coba menunjukkan perangkat tes memiliki nilai reliabilitas $=0,8$. Hasil uji validitas untuk tiap butir soal menggunakan koefesien product-moment berada pada kategori cukup hingga baik sekali. Daya pembeda dan tingkat kesukaran soal berada pada rentang cukup hingga sangat tinggi. $(0,5$ hingga 0,9$)$. Tingkat kesukaran soal bervariasi pada rentang sedang hingga sukar $(0,5$ hingga 0,9$)$. Ini menunjukkan perangkat tes sudah layak untuk digunakan. Perangkat tes dilengkapi dengan pedoman penskoran dan rubrik penilaian. Setiap soal memiliki bobot skor yang bervariasi. Data \% jumlah siswa dalam setiap kelompok prestasi yang memperoleh skor maksimal setiap nomor 

Siswa pada Konsep Asam-Basa menggunakan Kerangka DAC (Definition, Algorithmic, Conceptual)

soal dideskripsikan dalam bentuk grafik untuk dianalisis dan diinterpretasikan kecenderungannya. Skor maksimal merupakan skor yang menunjukkan jawaban siswa yang seluruhnya benar. Pola jawaban siswa yang tidak berhasil mencapai hasil maksimal dianalisis dan dideskripsikan untuk mendapatkan gambaran kemungkinan terjadinya kesalahan konsep agar dapat diberikan alternatif solusi untuk mengatasinya.

\section{HASIL DAN PEMBAHASAN}

Secara keseluruhan, persentase jumlah siswa yang pencapaian kemampuan representasi tertinggi adalah pada indikator soal ketujuh pada siswa kelompok prestasi sedang. Tipe soal C-I termasuk soal yang memerlukan kemampuan berpikir menginterpretasi dan menganalisis data. Kemampuan terendah pada indikator keempat, yaitu penyelesaian soal yang membutuhkan langkah-langkah pengerjaan secara matematis dan melibatkan rumus atau perhitungan yang berbeda.

Berikut dideskripsikan hasil penelitian setiap indikator soal. Indikator soal pertama dengan tipe soal $D-R U A$ diukur dengan menyajikan persamaan reaksi transfer proton antara $\mathrm{HS}^{-}$ dan HF:

$\mathrm{HS}^{-}(a q)+\mathrm{HF}(a q) \rightleftarrows \mathrm{F}^{-}(a q)+\mathrm{H}_{2} \mathrm{~S}(a q)$.

Siswa diminta untuk mengidentifikasi spesi asam dan basa berdasarkan persamaan reaksi tersebut dan memberikan alasannya. Pertanyaan tersebut mengukur kemampuan representasi simbolik ke submikroskopik, karena jawaban yang diharapkan adalah menentukan spesi yang memberikan proton (asam) dan spesi yang menerima proton (basa). Penyelesaian soal ini membutuhkan pemahaman tentang konsep asam-basa Bronsted Lowry: HF bersifat asam karena mendonorkan proton ke $\mathrm{HS}^{-}$sehingga menjadi $\mathrm{F}^{-}$, $\mathrm{HS}^{-}$bersifat basa karena proton yang dilepaskan $\mathrm{HF}$ sehingga menjadi $\mathrm{H}_{2} \mathrm{~S}$.

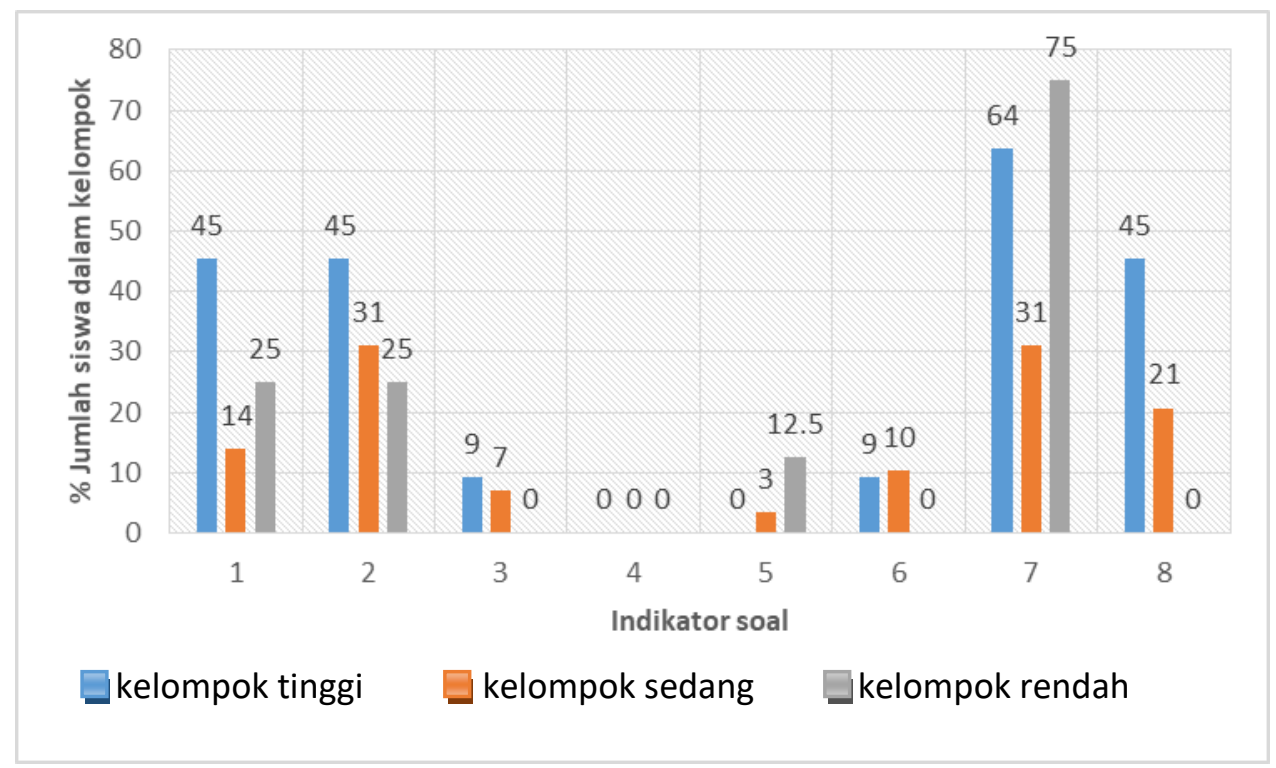

\section{Gambar 2. \% Jumlah Siswa Setiap Kelompok Prestasi dengan Skor Maksimal pada Setiap Indikator}


Pada Gambar 2, dapat dilihat kelompok prestasi tinggi paling banyak yang berhasil menjawab benar (skor maksimal). Siswa yang tidak mampu mengerjakan soal ini dengan benar, karena terbalik dalam mengidentifikasi spesi asam dan basa. Ada pula siswa yang benar mengidentifikasi spesi asam dan basa, namun keliru memberikan alasan. Mereka tampaknya mampu mengingat definisi asam basa Bronsted-Lowry, namun tidak dapat menerapkan definisi itu ketika memilih spesi yang mentransferkan proton atau menerima proton. Temuan serupa diperoleh dari penelitian Cooper et al. (2016), siswa cenderung memiliki kemampuan hanya pada level deskriptif untuk menjelaskan fenomena reaksi asam-basa. Mereka mampu mengenali spesi asam atau basa, namun tidak mampu menjelaskan mengapa spesi tersebut bersifat asam atau basa. Level eksplanasi sukar dicapai, karena dalam pembelajaran teori asam basa dijelaskan terpisah dari fenomena yang dihadapi siswa (Cartrette dan Mayo, 2011).

Untuk mengukur indikator soal kedua siswa diberikan soal algoritmik $(A)$ dengan menyajikan data makroskopik yaitu nilai $\mathrm{pH}$ dan volume suatu larutan (Ma) untuk direpresentasikan secara simbolik melalui perhitungan sehingga mendapatkan data mol ion hidroksida $(M i)$. Pertanyaan yang diajukan: "Hasil pengukuran $50 \mathrm{~mL}$ larutan $\mathrm{Mg}(\mathrm{OH})_{2}$ menggunakan indikator universal menunjukkan $\mathrm{pH}$ 13. Berapakan mol ion hidroksida yang terdapat dalam larutan tersebut! Pada soal ini terdapat keterkaitan antara konsep asam basa dalam perhitungan $\mathrm{pH}$ dengan konsep mol. Tipe soal $A-M a-M i$ ini membutuhkan konversi unit makroskopik (nilai $\mathrm{pH}$ dan volume) ke dalam unit submikroskopik (mol) atau mengukur kemampuan representasi makroskopik ke simbolik.
Persentase jumlah siswa tiap kelompok yang paling banyak mencapai hasil maksimal adalah kelompok siswa prestasi tinggi (Gambar 2). Siswa yang keliru menyelesaikan soal ini, tidak dapat menghubungkan data $\mathrm{pH}$ yang diketahui dengan konsep mol. Ada pula siswa yang sudah mengaitkan penyelesaian soal dengan konsep mol, namun terkecoh oleh rumus kimia $\mathrm{Mg}(\mathrm{OH})_{2}$, siswa menganggap bahwa konsentrasi $\mathrm{OH}^{-}$yang diperoleh dari penurunan data $\mathrm{pH}$ harus dibagi dua sesuai jumlah ion $\mathrm{OH}^{-}$yang tercantum dalam rumusnya. Sebagian besar siswa masih mengabaikan satuan dan penulisan ' $\mathrm{pH}$ ' dituliskan sama besar menjadi ' $\mathrm{PH}$ '. Hal ini dikarenakan terbiasanya siswa dalam penyelesaian soal secara matematis tidak menggunakan satuan, sebagaimana juga teridentifikasi pada penelitian lain (Bird, 2010); (Drechsler \& Schmidt, 2005); (Ozmen et al., 2009) ada indikator soal ketiga, siswa diminta untuk menentukan $\mathrm{pH}$ larutan berdasarkan data massa suatu zat yang dinyatakan dalam satuan mg. Penyelesaian soal dilakukan dengan mengkonversi satuan unit makroskopik menggunakan analisis multidimensional. Tipe soal $A-M a D$ ini berkaitan dengan perhitungan algoritmik $(A)$ yang dilandasi data-data makroskopik $(M a)$, sehingga perhitungan yang dilakukan termasuk kemampuan representasi makroskopik ke simbolik.

Berdasarkan Gambar 2 dapat dilihat, \% jumlah siswa yang berhasil mencapai skor maksimal di bawah 10\%, siswa kelompok prestasi rendah tidak satupun mampu menjawab dengan benar. Sebagian besar kesalahan yang dilakukan berkaitan dengan proses pengubahan satuan (analisis multi dimensional), yaitu konversi dari satuan mg ke gram, satuan mililiter ke liter dan pengubahan bilangan desimal ke bilangan pangkat negatif sepuluh atau penarikan

Jurnal Tadris Kimiya 3, 2 (Desember 2018): 158-170 
logaritma. Kesalahan juga terjadi sejak proses awal perhitungan. Siswa menggunakan data massa molar yang salah, ketika menghitung jumlah mol untuk mencari nilai $K_{a}$. Sebagaimana temuan pada indikator kedua, tampak siswa mengabaikan pentingnya penggunaan satuan pada proses perhitungan. Untuk itu guru kimia dalam pembelajaran hendaknya selalu memperhatikan pentingnya analisis dimensi dalam setiap perhitungan kimia agar siswa tidak terhindar dari hafalan rumus perhitungan (Dori dan Hameiri, 2014).

Pada indikator soal keempat, siswa diberikan soal algoritmik $(A)$ dengan menyajikan data makroskopik yaitu konsentrasi suatu larutan untuk direpresentasikan secara simbolik melalui beberapa langkah penyelesaian perhitungan $(M u)$. Dalam penyelesaian soal, siswa harus melalui beberapa tahap perhitungan untuk memperoleh jawaban yaitu terlebih dahulu siswa harus menemukan $\left[\mathrm{H}^{+}\right]$dari data $K_{a}$ baru mencari nilai $\mathrm{pH}$. Berdasarkan Gambar 2 dapat dilihat, tidak ada satupun siswa yang mampu menyelesaikan soal ini dengan benar atau mencapai hasil maksimal. Penelusuran data hasil jawaban siswa, menunjukkan hampir semua siswa menyelesaikan soal tersebut dengan menggunakan rumus perhitungan akar pangkat dua dari $K_{a}$ dikali konsentrasi larutan asam. Tidak ada siswa yang menghitung konsentrasi ion $\mathrm{H}^{+}$dalam larutan dengan menggunakan hukum kesetimbangan. Hal ini, karena larutan asam lemah mengalami kesetimbangan ion dalam air, sehingga konsentrasi larutan asam tidak sama dengan konsentrasi ion $\mathrm{H}^{+}$yang terlarut dalam air. Siswa yang menggunakan rumus perhitungan mampu mendapatkan hasil akhir yang hampir sama, namun tampaknya mereka hanya menggunakan rumus begitu saja tanpa memahami dari mana rumus perhitungan itu diperoleh. Ini menunjukkan siswa mampu menyelesaikan perhitungan, namun tidak dapat memahami konsep yang sebenarnya yang mendasari perhitungan tersebut. Lemahnya kemampuan siswa pada indikator ini diduga akibat siswa dalam pembelajaran mendapatkan rumus perhitungan $\mathrm{pH}$ secara instant tanpa dijelaskan konsep yang mendasari penurunan rumus tersebut, yaitu dari reaksi kesetimbangan ionisasi asam lemah (Sheppard, 2006).

Pada indikator soal kelima, siswa diberikan soal konseptual (C) dengan menyajikan data makroskopik yaitu fenomena dalam kehidupan berkaitan dengan asam basa untuk direpresentasikan dengan mengeksplanasi $(E)$ fenomena secara submikroskopik yang kemudian menuliskan secara simbolik melalui persamaan reaksi. Berdasarkan Gambar 2 dapat dilihat bahwa hanya $12,5 \%$ siswa kelompok tinggi dan $3 \%$ kelompok sedang yang dapat menjawab dengan benar. Hampir semua siswa mampu memberikan penjelasan siswa bagaimana proses hujan asam terjadi berdasarkan gambar yang diberikan. Namun mereka tidak dapat menghubungkan fenomena tersebut secara submikroskopik (keterkaitan dengan transfer proton) dan menuliskannya dengan benar ke representasi submikroskopik. Sebagian siswa sudah menuliskan persamaan reaksi yang terjadi, namun tidak lengkap melibatkan spesi-spesi yang bereaksi sebagaimana tercantum dalam gambar yang diberikan. Selain itu, pada penulisan persamaan reaksi tidak menuliskan fasa tiap zat yang bereaksi.

Indikator soal keenam diukur dengan menyajikan diagram representasi submikroskopik larutan yang berbeda kekuatan asam/basa, namun konsentrasi 
sama. Siswa diminta menganalisis diagram mengenai kecenderungan kekuatan asam disertai penjelasannya. Jumlah siswa terbanyak yang mencapai kemampuan representasi submikroskopik ke simbolik ini pada kelompok sedang (10\%), sedangkan kelompok rendah tidak satupun yang mampu menjawab dengan benar. Banyaknya siswa yang tidak memperoleh skor maksimal karena tidak mampu menginterpretasikan gambar sesuai fitur-fitur yang diberikan. Penginterpretasian tersebut memerlukan keterkaitan dengan perbedaan ionisasi yang terjadi pada asam lemah dengan asam kuat. Biasanya perbedaan itu hanya dituliskan dalam persamaan reaksi, untuk asam kuat reaksi ionisasi berlangsung sempurna, sedangkan asam lemah terionisasi sebagian. Untuk membandingkan kecenderungan kekuatan asam dari asam-asam lemah, selain dari besarnya harga $K_{a}$ dapat dilakukan dengan mentransformasi konsep tersebut ke dalam diagram submikrokopik. Sebagian besar siswa yang berhasil menentukan asam terkuat, memberikan yang keliru, yaitu menyatakan HY merupakan asam yang terkuat dibandingkan $\mathrm{HX}$ karena $\mathrm{HY}$ terionisasi sempurna. Padahal baik HY, maupun $\mathrm{HX}$ dua-duanya asam lemah. Ini berarti siswa tidak mampu menjelaskan alasannya secara submikroskopik sesuai dengan gambar yang tertera pada soal (simbolik). Diagram seperti ini tentu saja memerlukan penalaran logis terhadap fiturfitur representasi (Cooper et al., 2016).

Pada indikator soal ketujuh, siswa diberikan soal konseptual (C) dengan menyajikan data makroskopik berupa data $K_{a}$ dan $\mathrm{pH}$ asam (I). Selanjutnya siswa diminta untuk mengurutkan asam terlemah sampai terkuat beserta penjelasan secara submikroskopik. Pencapaian kemampuan representasi makroskopik ke submikroskopik pada indikator tujuh paling tinggi dibandingkan dengan indikator yang lain. $75 \%$ dari jumlah siswa kelompok tinggi mampu menjawab dengan benar, 64\% dari kelompok sedang dan paling sedikit dari kelompok rendah.

Hampir semua siswa yang keliru memberikan jawaban, terbalik dalam mengurutkan kecenderungan kekuatan keasaman. Mereka menyatakan jika $\mathrm{pH}$ rendah, maka tingkat keasamannya rendah. Ada dua kekeliruan yang mereka lakukan, yaitu mengurutkan kekuatan asam dengan merujuk pada harga $\mathrm{pH}$ dan menginterpretasikan kecenderungan harga $\mathrm{pH}$ dengan tingkat keasaman. Kekeliruan yang terjadi pada salah satu siswa kelompok tinggi adalah menggunakan nilai $K_{a}$ untuk menentukan kecenderungan tingkat keasaman, alasannya asam lemah harus ditentukan menggunakan data $K_{a}$ (tanpa memperhatikan nilai $\mathrm{pH}$ ). Demikian pula terjadi kesalahan memahami hubungan antara data nilai $\mathrm{pH}$ dengan konsentrasi $\mathrm{OH}$ Kekuatan asam bukanlah ditentukan oleh $\mathrm{pH}$, namun harga $K_{a}$ dari spesi asam tersebut. Sedangkan nilai $\mathrm{pH}$ menunjukkan konsentrasi ion $\mathrm{H}^{+}$yang terkandung dalam larutan. Semakin besar konsentrasi ion $\mathrm{H}^{+}$dalam larutan, semakin tinggi tingkat keasaman (semakin kecil pHnya). Sebaliknya semakin besar $\mathrm{pH}$, maka tingkat kebasaan larutan makin tinggi pula, karena konsentrasi ion $\mathrm{OH}^{-}$ dalam larutan semakin besar (Gilbert et al., 2018). Kekeliruan konsep siswa yang menganggap kekuatan asam basa ditentukan oleh pH juga ditemukan oleh Amry et al., (2017) dengan menggunakan instrumen tes two tier multiple choice.

Pada indikator soal kedelapan: siswa diberi dua keadaan yang berbeda mengenai suatu fenomena, siswa dapat memprediksi efek yang terjadi akibat kondisi yang berbeda disertai alasan secara submikroskopik. 
Fenomena yang diberikan adalah mengenai pengaruh hujan asam terhadap pertumbuhan tanaman.

Hampir separuh siswa kelompok tinggi dapat menyelesaikan soal ini dengan benar, namun kelompok rendah tidak dapat menjawab dengan benar. Banyak siswa yang tidak memperoleh skor maksimal dalam pertanyaan ini karena seharusnya jawaban pertanyaan ini dikaitkan dengan efek dari hujan asam. Air hujan yang bersifat asam dan turun ke bumi akan mempengaruhi apapun yang dilewatinya termasuk tanah. Tanah akan menyerap air hujan dan akan berpengaruh terhadap pertumbuhan tanaman termasuk pohon. Tanah akan mengalami perubahan $\mathrm{pH}$ menjadi lebih asam sehingga mengurangi kesuburan tanah dan menyebabkan ketersediaan unsur hara dalam tanah berkurang sehingga pohon yang berada di daerah industri akan mengalami kerusakan dibandingkan yang berada di pedesaan yang belum tercemar polusi dari industri dan kendaraan. Sesuai jawaban di atas siswa hanya menuliskan akibat yang terjadi pada pohon namun tidak mengkaitkannya dengan fenomena yang terjadi dalam kehidupan karena dalam soal sendiri sudah ada kata kunci yaitu di daerah industri dan lalu lintas yang padat. Siswa sudah mencantumkan terjadinya polusi namun tidak menjelaskan akibat yang terjadi dari polusi sehingga berdampak terhadap keberlanjutan sebuah pohon. Temuan tersebut mengindikasikan lemahnya kemampuan siswa menerapkan konsep ke dalam konteks kehidupan. Karena itu sangat penting untuk pembelajaran kimia seyogyanya tidak hanya ditujukan untuk penguasaan konsep saja namun penting untuk diintegrasikan ke dalam konteks kehidupan (Shwartz, et al., 2006) juga yang berkaitan dengan lingkungan (Farida et al., 2017).

\section{KESIMPULAN}

Berdasarkan analisis data hasil penelitian dan pembahasan mengenai analisis kemampuan tiga level representasi siswa menggunakan tes uraian berdasarkan kerangka DAC (Definition, Algoritmic, Conceptual) pada konsep asam basa: secara keseluruhan siswa lebih berhasil merepresentasikan makroskopik ke submikroskopik dibandingkan merepresentasikan simbolik ke submikroskopik, makroskopik ke simbolik dan submikroskopik ke simbolik. Persentase jumlah siswa yang pencapaian kemampuan representasi tertinggi pada kemampuan menginterpretasikan data ke konsep (type CI: Conceptual Interpretation) yang menghubungkan representasi makroskopik ke submikroskopik. Namun teridentifikasi adanya potensi miskonsepsi pada sebagian besar siswa mengenai konsep kekuatan asam-basa dan $\mathrm{pH}$. Persentase jumlah siswa yang pencapaiannya terendah pada kemampuan representasi makroskopiksimbolik, yaitu penyelesaian soal yang membutuhkan langkah-langkah pengerjaan secara matematis dan melibatkan rumus atau perhitungan yang beragam (type A-Mu: Alghoritmic Multistep). 
Analisis Kemampuan Tiga Level Representasi Siswa pada Konsep Asam-Basa menggunakan Kerangka DAC (Definition, Algorithmic, Conceptual)

\section{DAFTAR PUSTAKA}

Amry, U. W., Rahayu, S., \& Yahmin, Y. (2017). Analisis Miskonsepsi Asam Basa pada Pembelajaran Konvensional dan Dual Situated Learning Model (Dslm). Jurnal Pendidikan: Teori, Penelitian, dan Pengembangan, 2(3), 385-391.

Bayrak, B. K. (2013). Using Two-tier Test to Identify Primary Students' Conceptual Understanding and Alternative Conceptions in Acid Base. Mevlana International Journal of Education (MIJE), 3(2), 19-26.

Bird, L. (2010). Performance in General Chemistry. Journal of Chemical Education, 87(5), 541-546.

Cartrette, D. P., \& Mayo, P. M. (2011). Students' Understanding of Acids / Bases in Organic Chemistry Contexts. Chem. Educ. Res. Pract., 12, 29-39.

Cetin-dindar, A., \& Geban, O. (2011). Development of a Three-tier Test to Assess High School Students' Understanding of Acids and Bases. Procedia - Social and Behavioral Sciences, 15, 600-604.

Chandrasegaran, A. L., Treagust, D. F., \& Mocerino, M. (2007). The Development of A Two-tier Multiple-choice Diagnostic Instrument for Evaluating Secondary School Students' Ability to Describe an Explain Chemical Reactions Using Multiple Levels of Representation. Chemistry Education Research and Practice, 8(3), 293-307.

Cooper, M. M., Kouyoumdjian, H., \& Underwood, S. M. (2016). Investigating
Students' Reasoning about Acid-Base Reactions. Journal of Chemical Education, 93(10), 1703-1712.

Dori, Y. J., \& Hameiri, M. (2014). The "Mole Environment" Studyware: Applying Multidimensional Analysis to Quantitative Chemistry Problems. International Journal of Science Education, (September 2014), 37-41.

Drechsler, M., \& Schmidt, H. (2005). Textbooks' and Teachers' Understanding of Acid-base Models Used in Chemistry Teaching. Chemistry Education Research and Practice, 6(1), 19-35.

Farida, I. (2017). Evaluasi Pembelajaran Berdasarkan Kurikulum Nasional. Bandung: PT Remaja Rosda Karya.

Farida, I., Hadiansah, Mahmud, \& Munandar, A. (2017). Project-based Teaching and Learning Design for Internalization of Environmental Literacy with Islamic Values. Jurnal Pendidikan IPA Indonesia, 6(2), 277-284.

Farida, I., Liliasari, L., Sopandi, W., \& Widyantoro, D. H. (2017). A Web-based Model to Enhance Competency in The Interconnection of Multiple Levels of Representation for Pre-service Teachers. In Ideas for 21st Century Education (pp. 359-362). CRC Press.

Farida, I., Liliasari, L., Widyantoro, D. H., \& Sopandi, W. (2010). Representational Competence's Profile of Pre-Service Chemistry Teachers in Chemical Problem Solving. In 4th International Seminar of Science Education, Bandung (Vol. 30).

Gilbert, T. R., Kirss, R. V, Foster, N., Bretz, S. L., Jurnal Tadris Kimiya 3, 2 (Desember 2018): 158-170 
Analisis Kemampuan Tiga Level Representasi Siswa pada Konsep Asam-Basa menggunakan Kerangka DAC (Definition, Algorithmic, Conceptual)

\& Davies, G. (2018). Chemistry:The Science in Context. (E. Fahlgren, Ed.) (Fifth Ed). Newyork: W.W Norton \& Company.

Indriyani, P. (2013). Analisis Pemahaman Makroskopik, Mikroskopik, dan Simbolik Titrasi Asam-Basa Siswa Kelas XI IPA SMA serta Upaya Perbaikannya dengan Pendekatan Mikroskopik. Jurnal Pendidikan Sains, 1 (2 (Juni)), 109-120.

Michalchik, V., Rosenquist, A., Kozma, R., Kreikemeier, P., \& Schank, P. (2008). Visualization: Theory and Practice In Science Education. In J. K. Gilbert, M. Reiner, \& M. Nakhleh (Eds.), Representational Resources for Constructing Shared Understandings in the High School Chemistry Classroom (pp. 233-282). London: Springer Science.

Ozmen, H., Demircioglu, G., \& Coll, R. K. (2009). A Comparative Study of The Effects of a Concept Mapping Enhanced Laboratory Experience on Turkish High School Students' Understanding of Acidbase Chemistry. International Journal of Science and Matjematics Education, 7, 12.

Sheppard, K. (2006). High School Students' Understanding of Titrations and Related Acid-base Phenomena. Chemistry Education Research and Practice, 7(1), 32-45.

Shwartz, Y., Ben-Zvi, R., \& Hofstein, A. (2006). The Use of Scientific Literacy Taxonomy for Assessing The Development of Chemical Literacy Among High-school Students. Chemistry Education Research and Practice, 7(4), 203.
Smith, K. C., Nakhleh, M. B., \& Lowery, S. (2010). An Expanded Framework for Analyzing General Chemistry Exams. Chemistry Education Research and Practice, 11, 147-153.

Stoyanovich, C., Gandhi, A., \& Flynn, A. B. (2015). Acid-base Learning Outcomes for Students in an Introductory Organic Chemistry Course. Journal of Chemical Education, 92(2), 220-229. 